\title{
HISTOCHEMICAL STUDIES ON THE DEVELOPMENT OF CARPOPHORE OF COPRINUS KIMURAE
}

\author{
KAZUO KOMAGATA ${ }^{1}$ AND MASAHIKO OKUNISHI \\ Central Research Laboratories, Ajinomoto Co., Inc., \\ Kawasaki, Japan
}

(Received December 18, 1968)

\begin{abstract}
A process of development of Coprinus kimurae HoNGO et AOKI cultured in this laboratory was morphologically and histochemically observed. The process was tentatively divided into seven stages according to morphogenesis. Activities of cytochrome oxidase, succinic dehydrogenase, and acid and alkaline phosphatases were mainly found at active growth zones of this mushroom such as top part of stalk and margin of cap. Both kinds of phosphatases were not detected in gills at stages 3 and 4 but were detected in gills at stage 5 when cap grew remarkably and spores formed.
\end{abstract}

It is well known that mushrooms, taxonomically belonging to Basidiomycetes, form the fairly developed organs (carpophore). However, little has been known on the formation of carpophore to date, because there are difficulties in completing the life cycle of Basidiomycetes under artificial conditions. A study on the morphogenesis and differentiation in this group of microorganisms seems to be of interest, as its result may bring much useful informations on the cell differentiation of multicellular organisms.

The present authors isolated a strain of Coprinus kimurae which easily grows on the ordinary media and forms a complete carpophore in the laboratory. This paper deals with histochemical examinations on the distribution and changes of RNA and some enzymes during the normal development of carpophore of this fungus.

\section{MATERIALS AND METHODS}

Organism. A culture used in this investigation was isolated from the fresh tissue obtained from a carpophore grown on rice straw at Kawasaki in July, 1967, and identified with Coprinus kimurae HoNGO et AOKI (1) by the present authors. This fungus grew on malt extract agar $(1.25 \%$ malt extract, Difco) and well fructificated under an adequate condition. Tokyo

1 Present address: The Institute of Applied Microbiology, University of Tokyo, 
Cultural condition. When the fungus grew on malt extract agar plate and mycelial mat covered the plate after 7 days' incubation at $24^{\circ}, 8-\mathrm{mm}$ diameter discs were cut off from this agar plate with a cork borer, and the mycelial surface was faced to and placed on the new malt extract agar plate. The fungus inoculated by this manner was incubated at $24^{\circ}$ under white light (about $140 \mathrm{lux}$ ) and dark conditions at 12-hr intervals. After the primordia and carpophore formed, they were subjected to histochemical examination at various intervals.

Sectioning. For histological work, formalin-fixed, paraffin embedded sections were cut off about $10 \mu$ thick with a microtome. Gelatin-agar embedded and unfixed frozen sections were prepared for determination of enzymes because the carpophore tissue of $C$. kimurae was very delicate and fragile. The material was dipped in $5 \%$ gelatin solution for $5 \mathrm{~min}$ at $37^{\circ}$, then transferred to $5 \%$ gelatin-1.5\% agar solution for $3 \mathrm{~min}$ at $50^{\circ}$, and embedded in this medium. The embedded material prepared as mentioned above was hardened in a cold-chamber, followed by rapid freezing in Dry Ice-chilled hexane $\left(-70^{\circ}\right)$. The carpophore frozen in gelatin-agar was cut vertically (30 $\mu$ thick) in a cryostat chamber, and the sections were air-dried quickly. For large samples, tape-sectioning was employed. The surface of the frozen block was stuck with a Cellophane tape, and sections were cut off under the tape at desired thickness. The section was prevented from damage by the Cellophane tape, and staining could be made with the tape.

Staining. For histological work, iron-alum hematoxylin staining was used (2). RNA was stained with pyronine-methyl green (2). Succinic dehydrogenase was demonstrated by applying tetrazolium salt, and cytochrome oxidase was detected by applying $p$-aminodiphenylamine. Acid and alkaline phosphatases were stained with azo dyes. The procedures of staining were mainly those described by BURSTONE (3).

\section{RESULTS}

\section{General observation on carpophore development}

When the fungus developed from vegetative growth to reproductive stage, primordia of the carpophore formed. After the fungus was cultured for 3 days at $24^{\circ}$, the primordia appeared in a circular zone inside the margin of colony, like a fairly ring, as shown in Fig. 1. During this period, further growth of the colony was observed, and the second circular zone of primordia formed outside the first zone. When some primordia normally developed, the remaining ones tended to undevelop. The process from formation of primordia to maturation of carpophore involved the following seven morphological stages as illustrated in Fig. 2.

Stage 1: Primordia were noticed only as white spots of aggregation of hyphal mass.

Stage 2: At this stage, primordia looked like very small pin heads. 


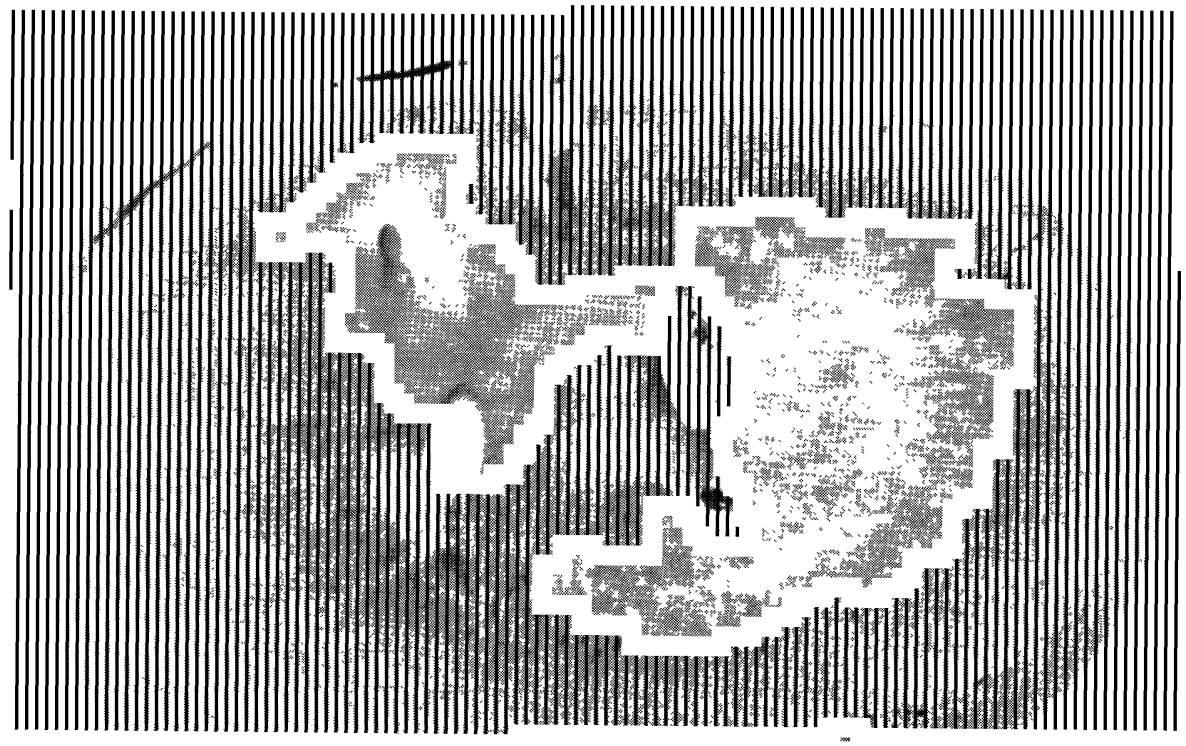

Fig. 1. Carpophore of Coprinus kimurae grown on malt extract agar at $24^{\circ}$ for 8 days.

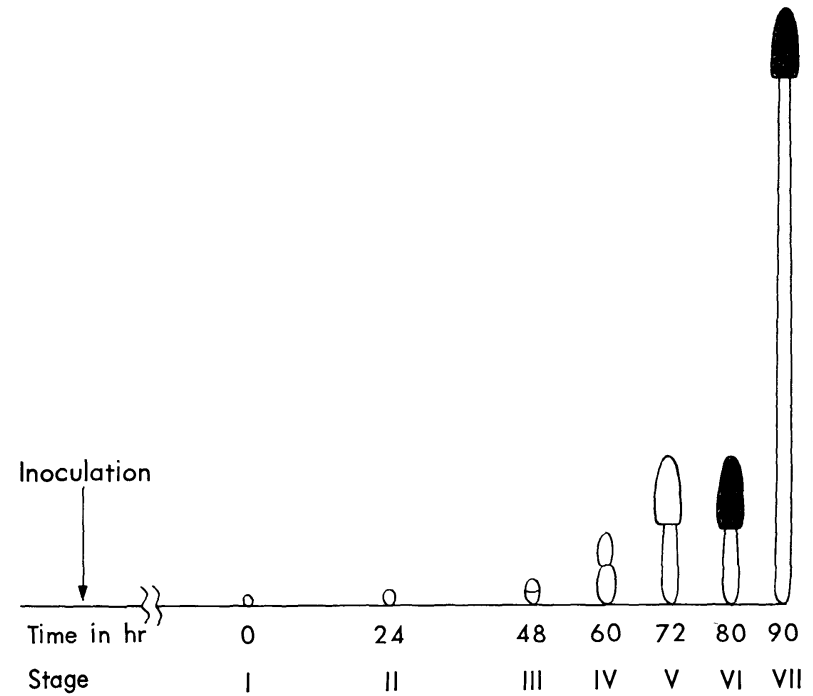

Fig. 2. Schematic illustration of morphogenesis of Coprinus kimurae. 
Stage 3: A white cap was distinguished from a darkish stalk by naked eyes.

Stage 4: Further growth of the cap and stalk was observed.

Stage 5: After the fungus grew to about $2 \mathrm{~cm}$ in height, elongation of the stalk decreased but the cap developed remarkably.

Stage 6: When the cap attained a mature size, its color changed from brown to dark brown.

Stage 7: The stalk elongated rapidly and reached about $10 \mathrm{~cm}$ in height, then expansion of the cap took place. Gills dissolved into liquid from a cap

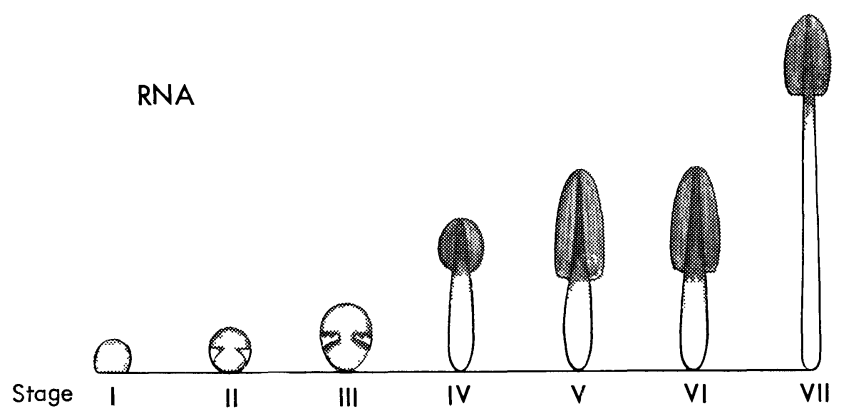

Succinic dehydrogenase

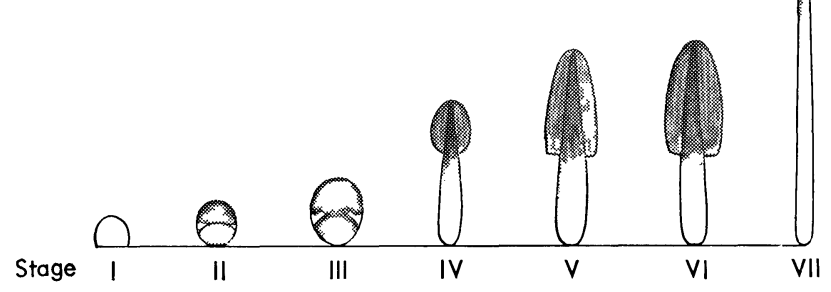

Acid and alkaline phosphatases

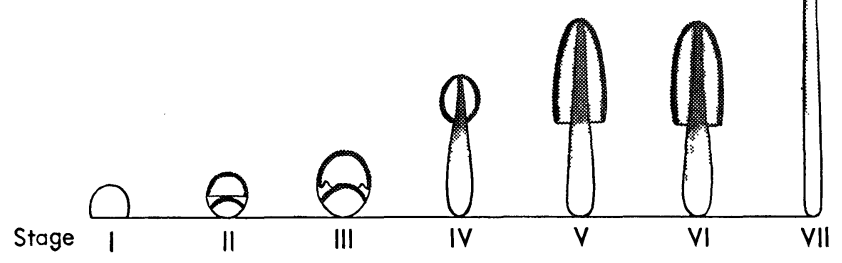

Fig. 3. Distribution of RNA, succinic dehydrogenase, and acid and alkaline phosphatases during development of Coprinus kimurae. 
margin, and simultaneously spores fell down from the cap.

Microscopic and histochemical observation of internal structure

Changes in internal structure of carpophore, and distribution of RNA and activities of cytochrome oxidase, succinic dehydrogenase, and phosphatases during the development of $C$. kimurae are summarized in Figs. 3 and 4.

Stage 1: This stage was regarded as the initial one of basidiocarp development. Hyphae tangled irregularly. RNA, and acid and alkaline phosphatases were distributed evenly but succinic dehydrogenase and cytochrome oxidase were obscure.

Stage 2: Vertical sections of this stage indicated the distinct polarity though clear morphological differentiation was not observed yet. Namely, radial orientation of hyphae was noticed at an apical region which developed into a cap in future, and vertical orientation was observed at a basal region which developed into a stalk. RNA, succinic dehydrogenase, and cytochrome oxidase were located at the future cap, and RNA was also detected at the future stalk. Both phosphatases were located at the upper surface of the future cap and upper region of the future stalk but not at the future gills.

Stage 3: Gills recognized distinctively, but basidia were not mature yet. Gaps appeared below the gills. Cells of the stalk became larger and were arranged vertically and regularly. RNA, cytochrome oxidase, and succinic dehydrogenase were located at the gills, the upper surface of cap, and stalk region below the cap. Both phosphatases were observed at the upper surface of cap and stalk region but not at the gills.

Stage 4: Cells of the stalk increased in diameter and length, but their histochemical characteristics were the same as those of stage 3 .

Stage 5: Basidiospores formed. Acid and alkaline phosphatases appeared in the gills and spores.

Stage 6 : Basidiospores matured. Brown coloration of the cap was ascribed to that of mature spores.

Stage 7: Sections showed a remarkable elongation of the cells of stalk.

\section{DISCUSSION}

As described above, a strain of $C$. kimurae showed a complete process of carpophore formation from primordia to maturation of basidiocarp under an artificial laboratory condition. The process was divided into seven distinct stages according to morphogenesis of carpophore. Concerning the development of the carpophore of mushrooms, BORRIS (4) and BONNER et al. (5) reported that active growth zones were found at the top part of stalk and the margin of cap. Present histochemical observation also demonstrated the active distribution of RNA, succinic dehydrogenase, cytochrome oxidase, and acid and alkaline phosphatases in such parts. Both kinds of phospha- 

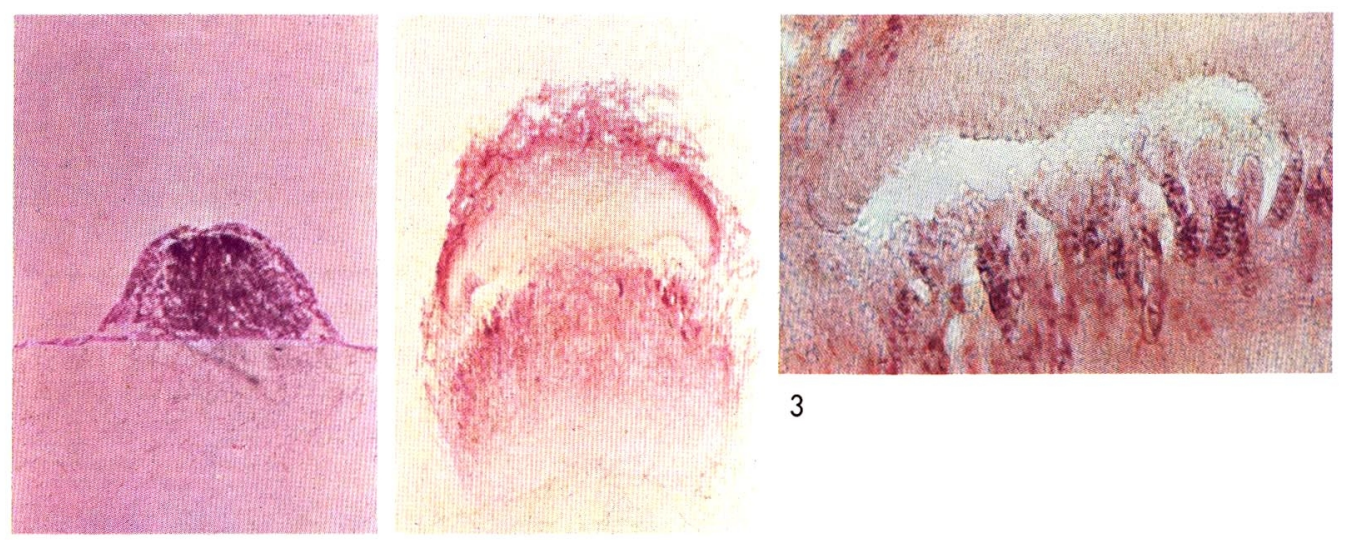

3

2
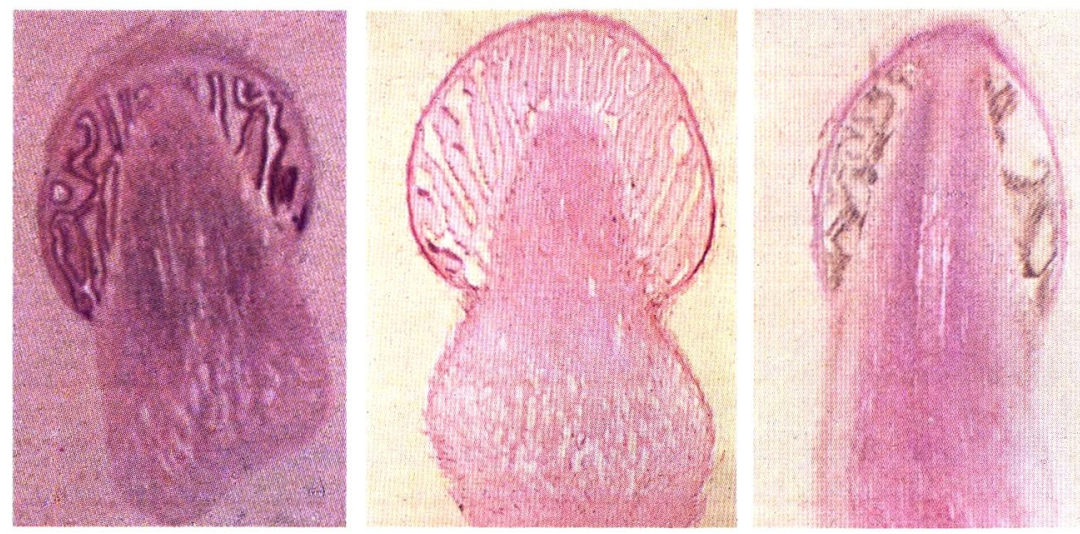

4

5

6
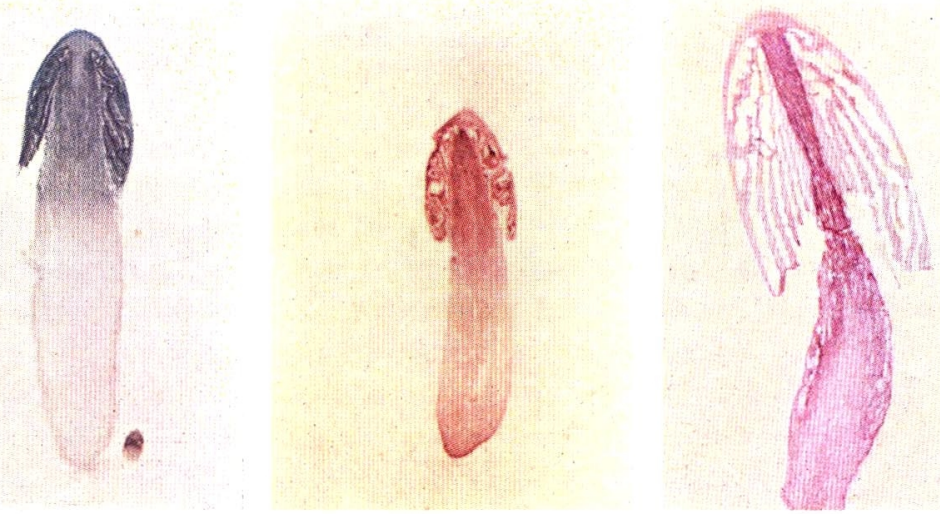
tases were not detected in gills at stages 3 and 4 . However, when the cap grew conspicuously (stage 5), the activities of such enzymes appeared in the gills, basidia, and spores. It is of interest that the activities of phosphatases appeared in the gills when the spores formed.

\section{REFERENCES}

1) M. Aoki and T. Hongo, Trans. Mycol. Soc. Japan, 7, 16 (1966).

2) K. Окамото, Microscopic Histochemistry, 3rd ed., Igaku Shoin Ltd., Tokyo (1965).

3) M.S. Burstone, Enzyme Histochemistry and Its Application in The Study of Neoplasms, Academic Press, Inc., New York (1962).

4) H. BORRIS, Planta, 22, 28 (1934).

5) J.T. Bonner, K. Kent Kane and Raphael H. Levey, Mycologia, 48, 13 (1956).

Fig. 4. Distribution of RNA and enzymes at various stages.

1. RNA at stage 1 stained with pyronine-methyl green.

2. Acid phosphatase at stage 3 stained with Naphthol AS-BI phosphate and Red Violet LB salt.

3. Acid phosphatase at stage 3 stained with Naphthol AS-BI phosphate and Red Violet LB salt (A part of gills is enlarged).

4. RNA at stage 4 stained with pyronine-methyl green.

5. Acid phosphatase at stage 4 stained with Naphthol AS-BI phosphate and Red Violet LB salt.

6. Alkaline phosphatase at stage 4 stained with Naphthol AS-BI phosphate and Red Violet LB salt.

7. Succinic dehydrogenase at stage 4 stained with Nitro-BT.

8. Cytochrome oxidase at stage 4. p-Aminodiphenylamine method.

9. Acid phosphatase at stage 5 stained with Naphthol AS-BI phosphate and Red Violet LB salt. 